\title{
Congenital peritoneal encapsulation presented with small bowel obstruction
}

\author{
Abdallah A. A. Mohamed (D), Fatma Mohammmed Al Shuraiqi, Salwa Al Sarhani, Sultan Ali Salim Al Busaidi and \\ Amer Ameen Joodi
}

\begin{abstract}
Background: Congenital peritoneal encapsulation is an extremely rare condition with an etiology based on abnormal embryonic gastrointestinal development. It is characterized by congenital development of an accessory peritoneal layer partially or entirely encapsulating the small bowel. The condition is poorly understood and often discovered incidentally, either intra-operatively or during autopsy. The majority of cases are asymptomatic and rarely complicated by small bowel obstruction. The preoperative diagnosis may be impossible by plain radiographs, which are often normal or may show signs of small bowel obstruction. Computed tomography (CT) may be helpful in preoperative diagnosis of congenital peritoneal encapsulation in a patient with obstruction.
\end{abstract}

Case presentation: We report a case of a 46-year-old male patient, who presented with features of intestinal obstruction; surprisingly, CT accurately suggested the diagnosis of peritoneal encapsulation which was confirmed at surgery.

Conclusions: The presence of physical signs such as asymmetrical and fixed abdominal distension can help the clinician to raise the suspicion of peritoneal encapsulation; however, CT in the right settings can confirm the diagnosis.

Keywords: Peritoneal encapsulation, Small bowel obstruction, Abdominal cocoon, Internal hernia, Computed tomography

\section{Background}

Congenital peritoneal encapsulation (CPE) is a rare congenital condition, characterized by the development of an accessory peritoneal layer by the 12th week of gestation which creates an accessory peritoneal sac that partially or completely encapsulates the small bowel [1-3]. The majority of the cases are asymptomatic, and few reported cases presented with bowel obstruction. Plain radiographs tend to be normal or show signs of small bowel obstruction; however, CT seems to be a very helpful tool in preoperative diagnosis, as well as, detecting any complications.

\footnotetext{
*Correspondence: abdallahahmed@gmail.com;

abdallah.abdallah@moh.gov.om

Department of Radiology, Nizwa Hospital, P.O. Box 1222, 611 Nizwa, Oman
}

\section{Case presentation}

A 46-year-old man presented to the Emergency Department with sudden onset of severe, diffuse, and colicky abdominal pain for the first time. The pain was associated with nausea and constipation for the last $24 \mathrm{~h}$. The patient is on $\mathrm{H}$. Pylori eradication therapy for peptic ulcer, and he has a surgical history of prosthetic lumbar spinal laminectomy.

On examination, the abdomen was distended with tender, palpable, and asymmetrical mass at the epigastric and central abdominal regions. Otherwise, he was hemodynamically stable with no evidence of fever or urinary symptoms. Abdominal radiographs were unremarkable.

CT was next performed which showed dilated and clustered small bowel loops giving the appearance of a cocoon (Fig. 1). They were encapsulated with a thin layer of peritoneum starting from the duodenojejunal junction to the terminal ileum, forming a tight sac (Fig. 2).
Springer Open (c) The Author(s). 2020 Open Access This article is licensed under a Creative Commons Attribution 4.0 International License, which permits use, sharing, adaptation, distribution and reproduction in any medium or format, as long as you give appropriate credit to the original author(s) and the source, provide a link to the Creative Commons licence, and indicate if changes were made. The images or other third party material in this article are included in the article's Creative Commons licence, unless indicated otherwise in a credit line to the material. If material is not included in the article's Creative Commons licence and your intended use is not permitted by statutory regulation or exceeds the permitted use, you will need to obtain permission directly from the copyright holder. To view a copy of this licence, visit http://creativecommons.org/licenses/by/4.0/. 


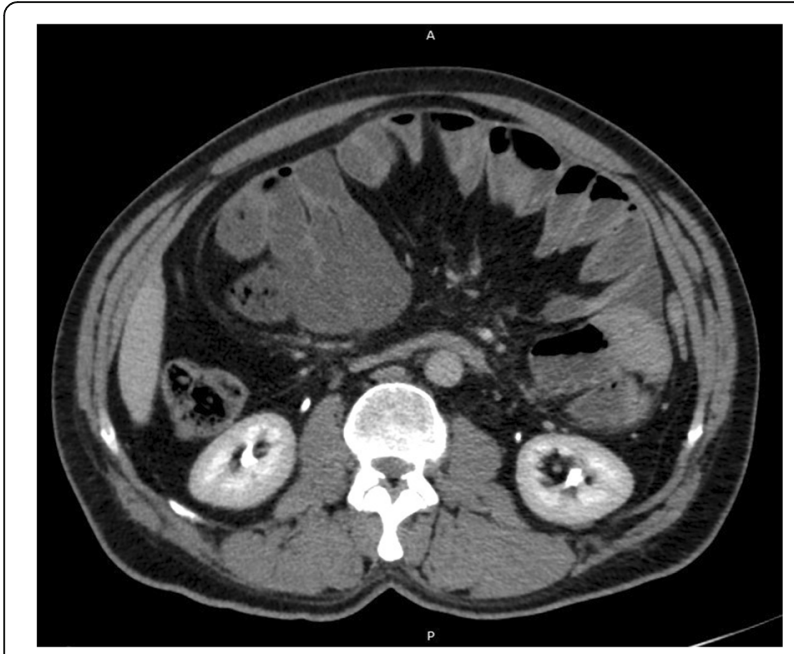

Fig. 1 Axial image from contrast-enhanced CT of the abdomen shows rounded, encapsulated cluster of small bowel loops

Sagittal reformatted images confirmed the appearance of the sac with displacement and splaying of the mesenteric vessels posterior to the sac (Figs. 3 and 4). The ascending and descending colons were posterolateral to the sac with no evidence of malrotation (Fig. 5). There was no evidence of bowel ischemia or perforation. The differential diagnosis for the appearance was internal hernia, abdominal cocoon, and peritoneal encapsulation.

The patient underwent laparotomy, where an accessory retroperitoneal sac encapsulating the entire small bowel

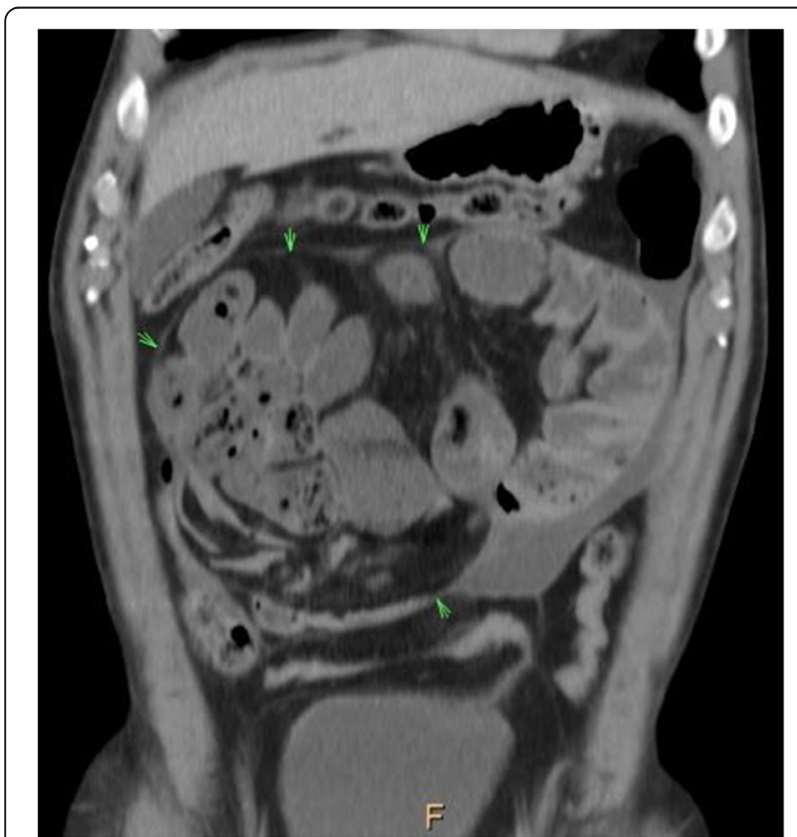

Fig. 2 Coronal reformatted image from contrast-enhanced CT of the abdomen demonstrating the thin peritoneal layer encapsulating the dilated small bowel loops

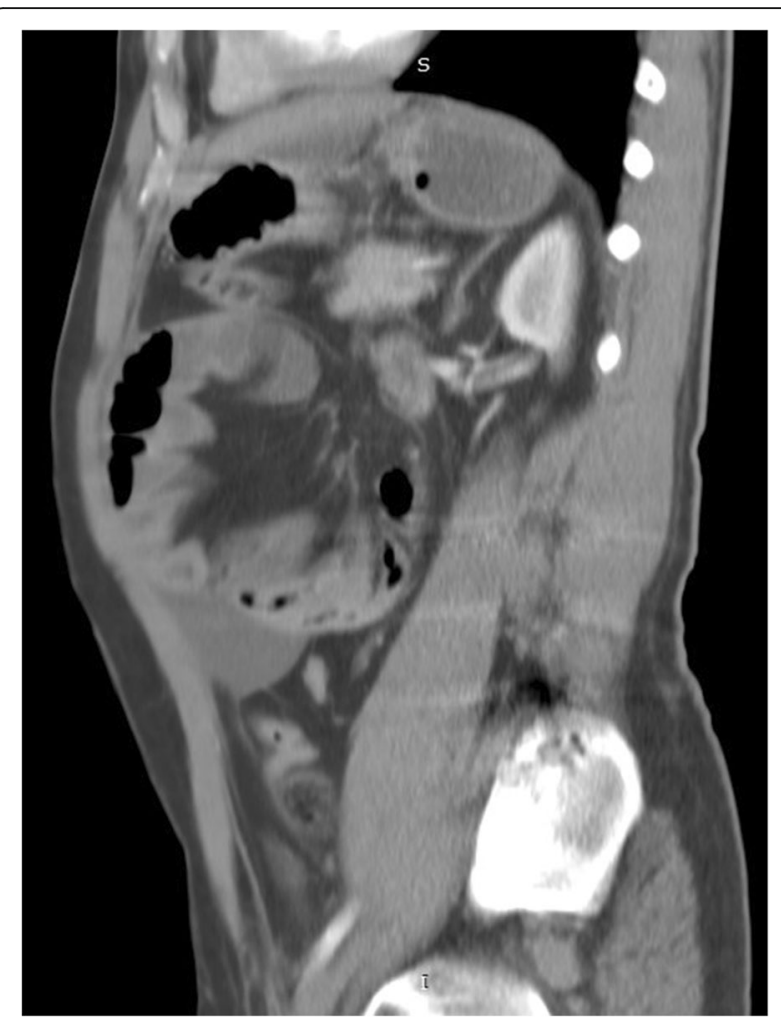

Fig. 3 Left paramidline sagittal reformatted image shows the tight sac containing the small bowel loops

was found distending the upper and central abdomen. The sac was opened, and the small bowel loops were found to be cocooned and greatly dilated with a lot of adhesions. Mechanical obstruction confirmed with transition zone at distal ileum. The membrane was resected and adhesiolysis achieved. There was no evidence of perforation or bowel infarction. Contents of the bowel were squeezed towards the cecum to reduce the distension and create a space to allow for abdominal closure. Postoperative period was uneventful and the patient discharged without complications.

\section{Discussion}

Peritoneal encapsulation (PE) is a general term used to describe three different entities: congenital peritoneal encapsulation (CPE), abdominal cocoon (AC), and sclerosing encapsulating peritonitis (SEP) [3].

Cleland was the first to describe CPE in 1868 as a rare congenital malformation resulting from the development of an accessory peritoneal membrane partially or completely encasing the small intestine and creating an accessory sac. To the best of our knowledge, less than 50 cases have been reported in the literature $[1,4]$.

Despite being poorly understood, few theories were suggested to explain the pathogenesis of CPE, and the most accepted one was postulated by Papez in 1932 . 


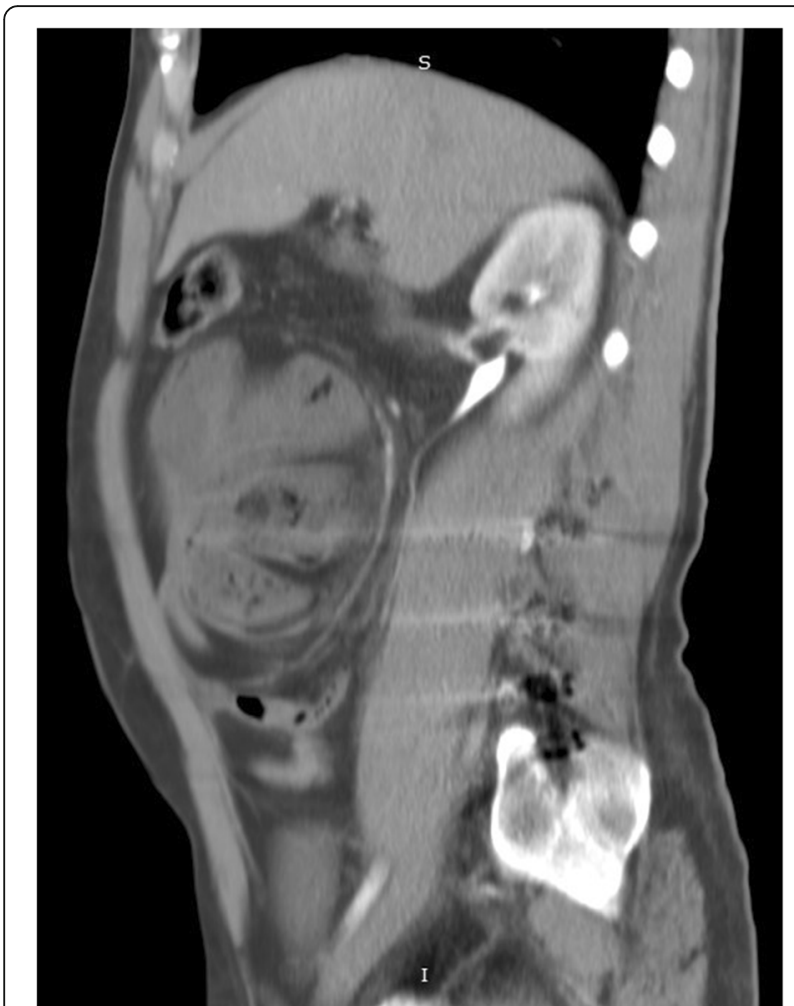

Fig. 4 Maximum intensity projection (MIP) sagittal reformatted image, showing the peritoneal sac splaying the mesenteric vessels and the cocooned, dilated small bowel loops within the sac. Note the horizontal streak artifact from lumbar metal prosthesis (not shown)

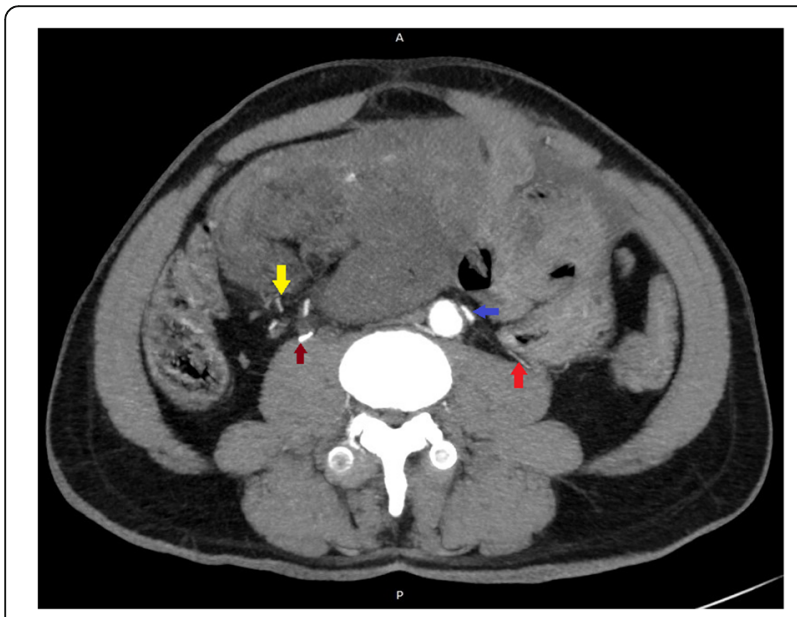

Fig. 5 Maximum intensity projection (MIP) axial image, showing the relation of the peritoneal sac to the inferior mesenteric artery (blue arrow), ascending left colic artery (red arrow), and ileocolic arterial branches (yellow arrow). The right ureter is opacified from prior contrast administration (black arrow)
Papez explained complex developmental pathogenesis, where adhesions develop between the linings of the physiological umbilical hernia and inferior duodenum which exerts a traction force over the sac harboring the mid-gut within the umbilical cord. Further adhesions develop between the peritoneal layers lining the sac and by the 12th week of gestation, when the hernia is reduced, an extraperitoneal accessory sac encasing the small bowel is formed [5].

$\mathrm{CPE}$ is usually asymptomatic, and the preoperative diagnosis is challenging as it is rarely complicated by intestinal obstruction. If small bowel obstruction is evident, plain radiographs probably will be able to detect the dilated small bowel loops or multiple air-fluid levels; however, CT may be able to detect the membranous capsule and the sac, as well as, any underlying complications [1]. Mimics such as paraduodenal hernias can be excluded by their specific CT appearance. A left paraduodenal hernia usually appears as a cluster of small bowel loops in the left anterior pararenal space and posterior to the descending colon, inferior mesenteric vein, and ascending left colic artery, in contrast to peritoneal encapsulation which is anterior to these structures (Fig. 5). A right paraduodenal hernia has a typical appearance posterior to the superior mesenteric vessels [6].

The case presented shows that CT was able to detect a thin membrane encasing clustered and obstructed small bowel loops (Fig. 1). Also, its anterior relation to the stretched mesenteric vessels (Figs. 4 and 5), as well as the presence of the ascending left colic artery posterior to the sac (Fig. 5), precluded the diagnosis of internal paraduodenal hernias [6] and suggested an alternative diagnosis of accessory peritoneal sac encapsulating the small bowel.

The two other peritoneal encapsulation conditions that should be differentiated from CPE are abdominal cocoon (AC) and sclerosing encapsulating peritonitis (SEP). Both conditions are acquired but with different pathogenesis and etiology [1].

AC was first described by Foo et al. in 1978 [7]. The etiology still poorly understood, and several theories were offered to explain the pathology. There is a general agreement that a status of subclinical peritonitis precedes AC. The underlying etiology includes retrograde menstruation with secondary viral infection, retrograde peritonitis, and various gynecological infections causing cell-mediated tissue damage [1, 7]. However, all theories failed to explain the fact that $\mathrm{AC}$ is twice more prevalent in males [1]. AC is an idiopathic condition and characterized by the formation of a thick fibrotic membrane that encases the bowel, forming a sac or cocoon along with some internal adhesions. The formed sac has an appearance similar to scar tissue, and histologically, it is characterized by the formation of a thick fibrotic 
membrane. The preoperative diagnosis may be achieved by identifying the thick fibrous membrane surrounding the bowel loops, a condition that is best visualized on a CT scan, which gives more accurate information on the degree of obstruction and the types of bowel loops involved. However, sometimes the surrounding membrane may be very thin and difficult to identify on a CT scan, making preoperative diagnosis difficult [8].

SEP-also known as encapsulating peritoneal sclerosis-is an acquired secondary condition to underlying disease process and by far more common compared to the two other entities [1]. It was first described in 1907 by Owtschinnikow [9]. The pathogenesis is similar to $\mathrm{AC}$ and characterized by the formation of a thick, fibrotic membrane secondary to various inflammatory abdominal conditions. Histologically, the formed fibroconnective membrane demonstrates inflammatory cellular infiltrates and dilated lymphatics; this is a very important differentiating point as compared to the normal peritoneal mesothelial lining of CPE [1]. The most common known etiology is peritoneal dialysis, and it has been estimated that $20 \%$ of peritoneal dialysis patients will develop SEP at 8 years after starting dialysis [10]. Other causes such as peritoneal shunts, tuberculosis, malignancy, and systemic illness had also been reported such as systemic lupus erythematosus, sarcoidosis, and Mediterranean fever $[1,9]$. CT features are variable, but usually a thick, enhancing membrane encapsulating bowel loops with or without peritoneal calcifications is identified. The formed sac is usually separated from the peritoneum but may have significant adhesions to the peritoneum and surrounding structures. Other imaging features such as peritoneal thickening, fluid loculations, and tethering of small bowel loops were considered pathognomonic for SEP [11].

\section{Conclusion}

Congenital peritoneal encapsulation is a rare congenital anomaly characterized by partial or total peritoneal encapsulation of the small bowel, whereas abdominal cocoon and sclerosing encapsulating peritonitis are believed to be secondary to inflammatory etiology. The presence of physical signs such as asymmetrical and fixed abdominal distension can help the clinician to suspect the diagnosis of PE. The novelty of the case presented that it shows how CT is a very helpful tool in outweighing the diagnosis of peritoneal encapsulation over other differentials.

\section{Abbreviations}

$\mathrm{CT}$ : Computed tomography; CPE: Congenital peritoneal encapsulation; PE: Peritoneal encapsulation; AC: Abdominal cocoon; SEP: Sclerosing encapsulating peritonitis

\section{Authors' contributions}

All authors have read and approved the manuscript. AM: data collection, writing, designing, and editing the manuscript. FS and SS: revision and editing of the manuscript. SB and AJ: selection and preparation of figures

\section{Funding}

None.

\section{Availability of data and materials}

The data used during the current study preparation are available from the corresponding author on reasonable request.

\section{Ethics approval and consent to participate}

This study was approved by the local research committee in Nizwa hospital on April 1, 2020, and by the regional ethics and research committee of a Dakhiliyah region on April 4, 2020

\section{Consent for publication}

Written informed consent was obtained for publication of this case report and accompanying images. A copy of the consent is available for review by the Editor-in-Chief of this journal on request.

\section{Competing interests}

We declare no conflict of interests prior and during the preparation of this paper.

Received: 7 April 2020 Accepted: 12 August 2020

Published online: 26 August 2020

\section{References}

1. Dave A, McMahon J, Zahid A (2019) Congenital peritoneal encapsulation: a review and novel classification system. World J Gastroenterol. 25(19):22942307. https://doi.org/10.3748/wjg.v25.i19.2294

2. Teixeira D, Costa V, Costa P, Alpoim C, Correia P (2015) Congenital peritoneal encapsulation. World J Gastrointest Surg. 7(8):174-177. https:// doi.org/10.4240/wjgs.v7.i8.174

3. Naraynsingh V, Maharaj D, Singh M, Ramdass MJ (2001) Peritoneal encapsulation: a preoperative diagnosis is possible. Postgrad Med J. 77(913): 725-726. https://doi.org/10.1136/pmj.77.913.725

4. Cleland (1868) On an abnormal arrangement of the peritoneum, with remarks on the development of the mesocolon. J Anat Physiol. 2(2):201-206

5. Papez JW (1932) A rare intestinal anomaly of embryonic origin. Anat Rec. 54:197-198

6. Doishita S, Takeshita T, Uchima Y et. al. Internal hernias in the era of multidetector CT: correlation of imaging and surgical findings. Radiographics. 2016;36 (1): 88-106.

7. Foo KT, Ng KC, Rauff A, Foong WC, Sinniah R (1978) Unusual small intestinal obstruction in adolescent girls: the abdominal cocoon. Br J Surg. 65:427430

8. Gupta S, Shirahatti RG, Anand J (2004) CT findings of an abdominal cocoon. AJR Am J Roentgenol. 183(6):1658-1660. https://doi.org/10.2214/ajr.183.6. 01831658

9. Owtschinnikow P (1907) Peritonitis chronica fibrosa incapsulata. Arch für Klin Chir. 83:623-634

10. Brown EA, Bargman J, van Biesen W et al (2017) Length of time on peritoneal dialysis and encapsulating peritoneal sclerosis - position paper for ISPD: 2017 Update. Perit Dial Int. 37(4):362-374. https://doi.org/10.3747/ pdi.2017.00018

11. Vlijm A, van Schuppen J, Lamers AB, Struijk DG, Krediet RT (2011) Imaging in encapsulating peritoneal sclerosis. NDT Plus. 4(5):281-284. https://doi.org/10. 1093/ndtplus/sfr068

\section{Publisher's Note}

Springer Nature remains neutral with regard to jurisdictional claims in published maps and institutional affiliations. 